\title{
PREVALENCE, DIAGNOSTICS AND TREATMENT OF OVARIAN FOLLICULAR CYSTS IN DAIRY COWS
}

\author{
G. Naglis \\ PhD Student at the Department of Obstetrics, Reproduction and Reproduction Disorders \\ Faculty of Veterinary Medicine, Trakia University, Stara Zagora, Bulgaria
}

\begin{abstract}
Ovarian cysts are among the primary causes for poor reproduction efficiency and economic losses in dairy cattle farming. Material and metods: The studies were performed in 2015-2017 in three dairy cattle farms.In the experiment, 79 cows with follicular ovarian cysts were divided randomly into 3 groups. To the first group $(\mathrm{n}=33)$, a standard double Ovsynch was applied with $0.01 \mathrm{mg} \mathrm{GnRH}$ (Veterelin, Laboratorios Calier, Spain) on day 0, $150 \mu \mathrm{g}$ PGF2 $\alpha$ (D - Cloprosstenolsodium, Indupart, Vetpharma Animal Health, Spain) on day 7, $0.01 \mathrm{mg}$ GnRH (Veterelin, Laboratorios Calier, Spain) on day 10, and after 7 days, Ovsynch (GnRH-PGF-GnRH). The cows from the second group $(n=28)$ were submitted to double Ovsynch and additional progesterone treatment through placement of Controlled Internal Drug Release device (EAZI BREED CIDR Cattle insert, 1.38 g progesterone; Pfizer Animal Health, USA) for 7 days between the first GnRH at day 0 and prostaglandin on day 7 . The control group comprised 18 untreated cows. Results: First-service conception rate in cows treated by double Ovsynch and vaginal inserts was higher $28.6 \%$ compared to that in standard double Ovsynch: $24.2 \%$. Cumulative pregnancy percentage after applied treatments was $60.7 \%$ in double Ovsynch plus progesterone and $54.5 \%$ in standard double Ovsynch.
\end{abstract}

Key words: cows, follicular cysts, double Ovsynch

\section{INTRODUCTION}

Ovarian cysts are among the primary causes for poor reproduction efficiency and economic losses in dairy cattle farming. Negative effects on cattle reproduction comprise increased calving-to-first estrus intervals and calving-tofirst service intervals by approximately 13 and 33 days, respectively. This state is characterised with large, permanent anovulatory follicles in ovaries resulting from improper neuroendocrine control on the rhythmic estrus course and ovulation $(1,2)$.

The incidence of the condition in various herds and countries ranges from $6.7 \%$ and $13.1 \%$ (3, 4). Cows with dystocia, retention of placenta, metritis, ketosis and lameness are at 1.4 to 2.9 greater risks for development of ovarian cysts compared to cows with normal parturition and postpartum periods $(5,6)$.

Rectal examination is most commonly used for detection of ovarian cysts. This method is efficient although false positive diagnoses are approximately $10 \%$ due to large follicles, corpus luteum or cavitated corpus luteum. Studies demonstrated accurate diagnosis in $50 \%$ of cases (7). Diagnostic ultrasound is a reliable technique for detection of cysts. The ovarian structures are visualised and could be clearly differentiated.

Gonadotropin-releasing hormone is most commonly used for treatment of follicular cysts. The Ovsynch protocol for programmed artificial insemination was also successfully used for treatment of ovarian cysts (8). The modified Ovsynch protocol combining PGF $2 \alpha$ with first GnRH treatment increases the odds for conception compared to standard Ovsynch (9). Another possibility for ovarian cysts treatment is application of progesterone. The placement of intravaginal devices releasing progesterone for 9 to 12 days reduces $\mathrm{LH}$ secretion, leads to regression of the cyst and follicular wave within 5 days after device placement (10). 


\section{MATERIAL AND METHODS}

\section{Experimental animals}

The studies were performed in 2015-2018 in three Holstein dairy cattle farms in southeastern Bulgaria - in Venets, Burgas district (198), in Samuilovo, Sliven district (326) and Dyadovo, Sliven district (188). All cows were housed in free stalls, machine milked three times daily, with implemented automated Heat-time and De Laval, Vestfalia estrus detection systems, constant access to feed (total mix ration) and water. All examinations were in line with regulations for humane treatment of animals.

\section{Hormonal treatment}

The hormonal treatment included: $0.01 \mathrm{mg}$ GnRH (Veterelin, Laboratorios Calier, Spain) on day $0,150 \mu \mathrm{g}$ PGF2 $\alpha$ (D -Cloprosstenolsodium, Indupart, Vetpharma Animal Health, Spain) on day 7, $0.01 \mathrm{mg}$ GnRH (Veterelin, Laboratorios Calier, Spain) on day 10, additional placement of Controlled Internal Drug Release device (EAZI BREED CIDR Cattle insert, $1.38 \mathrm{~g}$ progesterone; Pfizer Animal Health, USA) for 7 days between the first GnRH at day 0 and prostaglandin on day 7. The protocol continued with $0.01 \mathrm{mg} \mathrm{GnRH}$ (D - Cloprosstenolsodium, Veterelin, Laboratorios Calier, Spain) on day 17, $150 \mu \mathrm{g}$ PGF2 $\alpha$ (Indupart, Vetpharma Animal Health, Spain) on day 24 and $0.01 \mathrm{mg}$ GnRH (Veterelin, Laboratorios Calier, Spain) on day 26.
All treatments of cows were performed between $16.00-16.30 \mathrm{~h}$ on the respective day.

\section{Experimental design}

The survey was conducted from May 2015 to April 2018 in mentioned cattle farms. All cows were housed in free stalls, machine milked three times daily, had constant access to a total mix ration and water. The experiment included 83 cows without signs of estrus by the $45^{\text {th }}$ postpartum day. The average milk yield to the beginning of the experiment was $30.3 \pm 3.41$.

The animals were examined twice at 10-day intervals by ultrasonography between the $45^{\text {th }}$ and the $60^{\text {th }}$ day for detection of ovarian finding. Cows with follicular ovarian cysts were divided randomly into 3 groups. At the time of the second examination, blood samples were collected for assay of progesterone levels. To the first group $(n=33)$, a standard double Ovsynch was applied. It included 12 primiparous and 21 multiparous cows. The cows from the second group $(n=28)$ were submitted to double Ovsynch and additional progesterone treatment through CIDR (Figure 1). The cows were 9 primiparous and 19 multiparous. The control untreated group $(\mathrm{n}=18)$ comprised 6 primiparous and 12 multiparous cows.

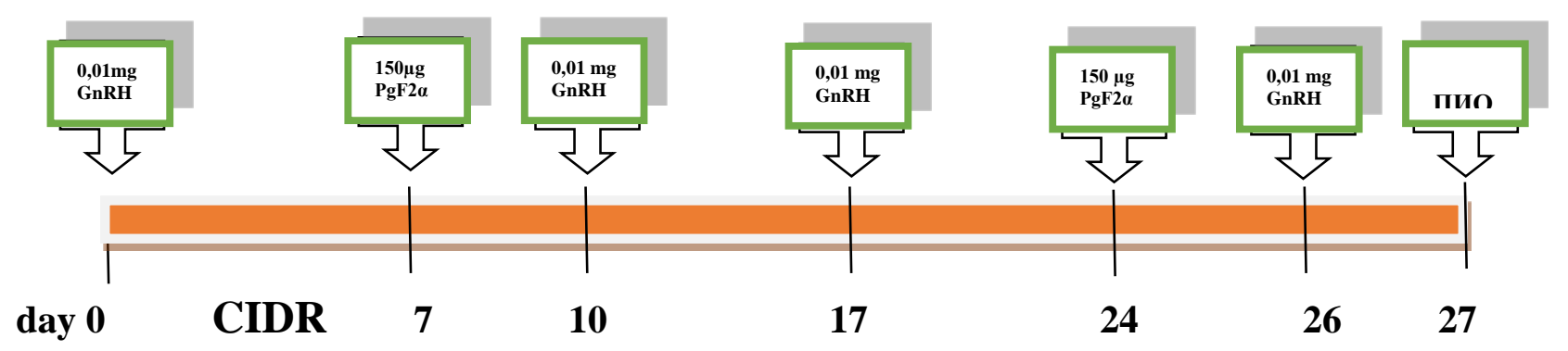

Figure 1. Standard Double Ovsynch and double Ovsynch plus progesterone protocols

During the ultrasonography of ovaries on days 10,17 and 24, the luteinisation of follicular cyst wall was evaluated.

Data were processed by StatSoft software (Statistica 7, Microsoft Corp. 1984-2000 Inc.). They were expressed as mean and standard deviation (SD), relative proportion (\%). Level of significance was set at $\mathrm{p}<0.05$.

\section{RESULTS}

Ovarian cysts were detected by rectal examination and ultrasound. BY means of ultrasonography, accurate diagnosis for follicular cyst presence was made in $92 \%$ of cases, while differentiation of luteal cysts and cavitated yellow body was done in $83 \%$ of cases.

The incidence of ovarian cysts in this survey was $12.9 \%(n=113)$ of all cows for the period. The highest relative proportion of follicular cysts was found in farm C $-16.14 \%$, followed by farms A: $11.93 \%$ and B: $11.82 \%$. Luteal cysts were registered in $2.7 \%$ and follicular in $10.2 \%$ of cases. The highest incidence of follicular cysts was found out in spring and summer $-6.1 \%$ while the autumn-winter incidence was $4.1 \%$. Seasonal prevalence of luteal cysts was not observed. With respect to 
the number of lactation, the highest incidence of cysts was in cows in second lactation
(43.8\%) followed by third lactation (23.6\%) and first lactation (21.4\%) (Figure 2).

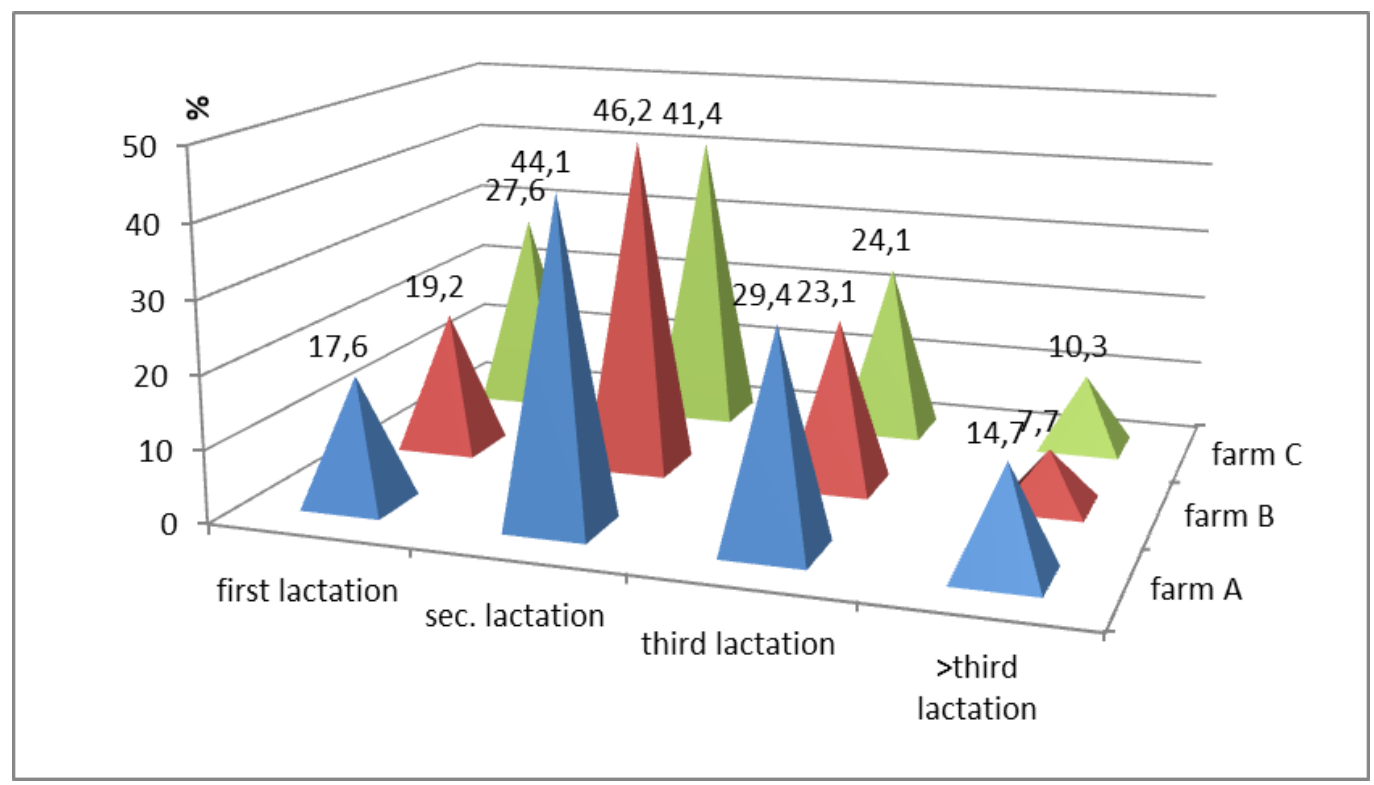

Figure 2. Prevalence of ovarian cysts depending on the lactation number

Depending on postpartum day of detection, the most numerous cysts were demonstrated between postpartum days 30 and $60-41.6 \%$ (Figure 3). No significant difference in the incidence of follicular cysts with regard to daily milk yield was observed. Marked luteinisation of the follicular wall was observed between post treatment days 17 and 24.

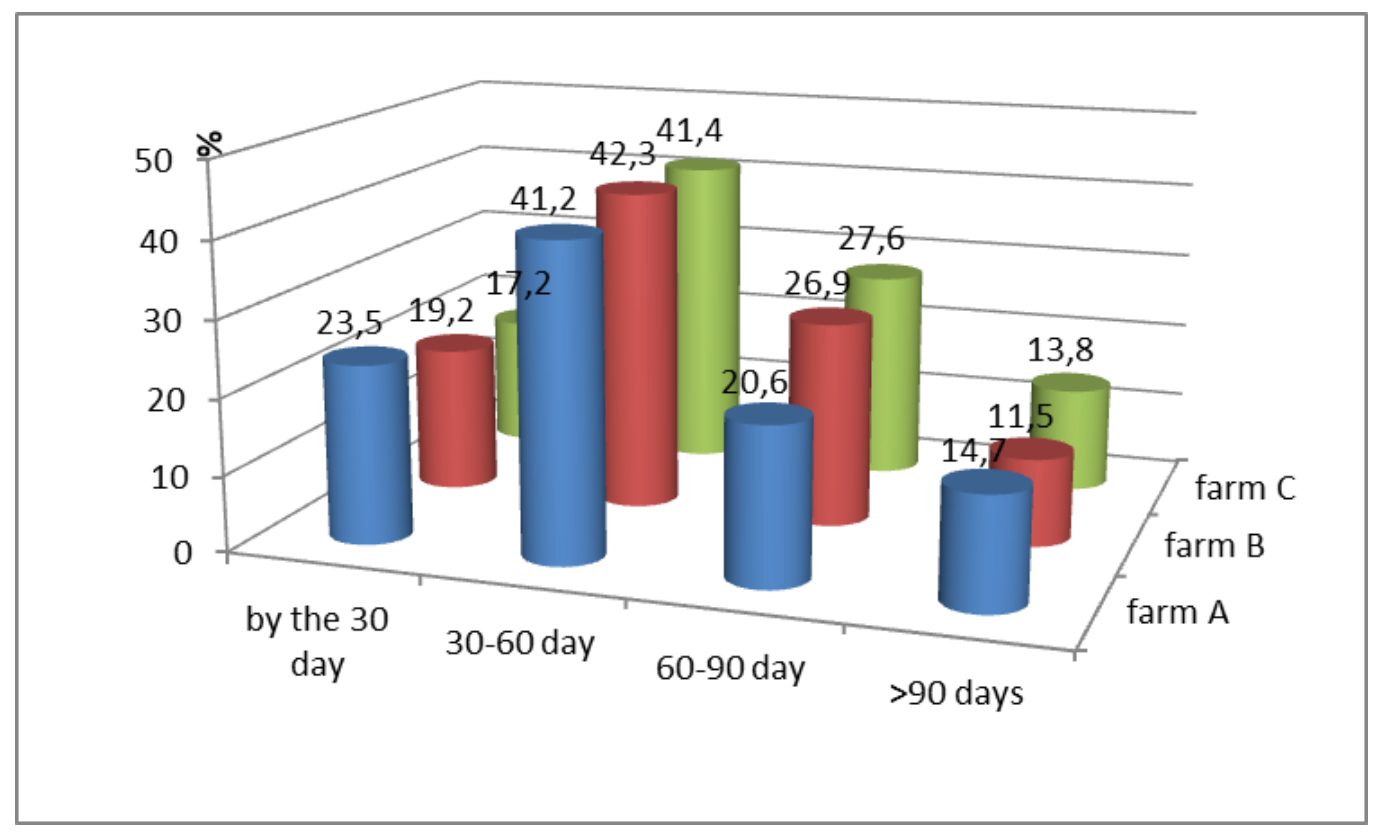

Figure 3. Prevalence of ovarian cysts depending on postpartum day of detection

In cows treated with double Ovsynch and vaginal inserts, higher first-service conception rate was registered: $28.6 \%$ and $2.5 \pm 1.4$ inseminations. In the group with double Ovsynch, conception rate was $24.2 \%$, with
2.18 \pm 1.19 inseminations. Cumulative pregnancy rate of applied treatments was $60.7 \%$ in the double Ovsynch group + progesterone and $54.5 \%$ in the standard Ovsynch group (Table 1). 
Table 1. Results depending on the applied treatment

\begin{tabular}{|l|c|c|c|}
\hline & $\begin{array}{c}\text { Follicula } \\
\text { r cysts } \\
(\mathbf{n})\end{array}$ & $\begin{array}{c}\text { First-service } \\
\text { conception rate }\end{array}$ & $\begin{array}{c}\text { Cumulative } \\
\text { pregnancy rate }\end{array}$ \\
\hline Standart Double Ovsynch & 33 & $24.2(8)$ & $54.5(18)$ \\
\hline Double Ovsynch + CIDR & 28 & $28.6(8)$ & $60.7(17)$ \\
\hline Control & 18 & & \\
\hline
\end{tabular}

\section{DISCUSSION}

Ovarian follicular cysts were detected on the basis of presence of fluid-filled structure, fluctuation and thin wall found during the rectal exam, and visualisation of the structure in the ultrasound exam. Ovarian follicular cysts are determined as fluid-filled structures with diameter $\geq 35 \mathrm{~mm}$ which are retained for more than 10 days in absence of corpus luteum $(1,2)$. Follicular and luteal cysts could be distinguished by wall thickness. Cyst wall thickness of follicular cysts is $\leq 3 \mathrm{~mm}$, and that of luteal cysts $>3 \mathrm{~mm}$. On the basis of these criteria, accurate diagnosis is posed in about $85 \%$ of cases (7). In our studies, accurate diagnosis of follicular cyst by means of ultrasound was posed in $92 \%$ of cows whereas the differentiation of luteal cysts from corpus luteum was observed in $83 \%$ of cases.

The incidence of cysts did not always correlate in average daily milk yields at farms. Our results confirmed the theory for occurrence of higher percentage of cysts with high milk yield only at one of farms. Fleischer et al (2001) established triple incidence of ovarian cysts along with twofold increase of milk yields $(9 \%$ and $27 \%$ incidence for lactations with 6,000 and $12,000 \mathrm{~kg}$ milk respectively) (3).

The highest relative proportion of ovarian cysts in our study was found out during the second lactation: $43.66 \%$. Our results confirmed the reports of Grohn et al (1990) and Fleischer et al (2001) $(3,11)$. The incidence of ovarian cysts increased parallelly to parturitions. In the first lactation, the relative share of cows with cysts was by $40 \%$ to $80 \%$ lower than in the general population (12).

The results from the present study with respect to the time of detection of ovarian cysts confirmed that the peak was until the $60^{\text {th }}$ postpartum day $(9,13)$.

Gonadotropin releasing hormone $(\mathrm{GnRH})$ is most commonly used for treatment of follicular cysts. The treatment induces immediately increase of LG production and luteinisation of the cyst. The present follicular cyst does not ovulate, but follicles of the available follicular wave are developed and some of them could ovulate at the time of the treatment. After luteinisation, steroid synthesis switches from estradiol to progesterone, and thus the cyst becomes susceptible to prostaglandin (2).

The used combinations resulted in estrus within $10.0 \pm 2.1$ and $24.0 \pm 4.4$ days and conception rates of $24.2 \%$ and $28.6 \%$. Similar data were reported by Dinsmore et al (1987), according to which the return to normal cyclic activity has occurred in $72 \%$ to $85 \%$ of cows treated with GnRH within 19-23 days (14). The conception rate during the first estrus was $46 \%-58 \%$, relatively higher than that in the present study. Comparative studies on buserelin (a GnRH analogue) and human chorionic gonadotropin (hHG) showed similar results (15).

The Ovsynch protocol, intended for fixed-time artificial insemination, was also successfully used for treatment of ovarian cysts. In experiments with a large animal cohort $(3000$ lactating cows), a similar conception rate was reported $(\sim 27 \%)$ with the Ovsynch protocol $(8,16)$. The modified Ovsynch, combining PGF $2 \alpha$ with the first GnRH treatment increased the odds for conception compared to the standard protocol (5).

6

In progesterone-stimulated cows, estrus occurred on the average $15.5 \pm 1.8$ days after placement of vaginal inserts. Progesterone restored the sensitivity of the hypothalamus to estradiol through positive feedback. The occurrence of estrus and subsequent ovulation occurred up to 7 days after removal of the vaginal insert and real conception rates of $18 \%$ to $28 \%$ (7). A longer interval, up to 10 days after removal of vaginal inserts was reported by Todoroki et al (2001) and Todoroki et al (2004).

\section{CONCLUSION}

The obtained results show that the administration of standard and double Ossinch with further progesterone treatment in dairy cows with follicular cysts in the ovaries may be used to treat the same and result in improved fertility

\section{ACKNOWLEDGMENTS}

Thanks to the owners of the cattle farms for the opportunity to carry out the survey. 


\section{REFERENCES}

1. Garverick, H A., Ovarian follicular cysts in dairy cows. J Dairy Sci; 80: 995-1004, 1997.

2. Wiltbank, MC., Gumen, A., Sartori, R., Physiological classification of anovulatory conditions in cattle. Theriogenology; 57: 2152, 2002.

3. Fleischer, P., Metzner, M., Beyerbach, M., The relationship between milk yield and the incidence of some diseases in dairy cows. $J$ Dairy Sci, 84: 2025-2035, 2001.

4. Hooijer, GA., Lubbers, RB., Ducro, BJ., et al., Genetic parameters for cystic ovarian disease in dutch black and white dairy cattle. J Dairy Sci, , 84, 286-291, 2001.

5. Lopez-Gatius, F., Santolaria, P., Yaniz, J., et al. Risk factors for postpartum ovarian cysts and their spontaneous recovery or persistence in lactating dairy cows. Theriogenology, 58: 1623-1632, 2002.

6. Melendez, P., Bartolome, J., Archbald, LF., et al., The association between lameness, ovarian cysts and fertility in lactating dairy cows. Theriogenology, 59: 927-937, 2003.

7. Douthwaite, R. and Dobson H., Comparison of different methods of diagnosis of cystic ovarian disease in cattle and an assessment of its treatment with a progesterone-releasing intravaginal device. Vet Rec, 147: 355-359, 2000.

8. Bartolome, J., Hernandez, J., Sheerin, P., et al., Effect of pretreatment with bovine somatotropin (bST) and/or gonadotropinreleasing hormone $(\mathrm{GnRH})$ on conception rate of dairy cows with ovarian cysts subjected to synchronization of ovulation and timed insemination. Theriogenology, 59: 1991-1997, 2003.

9. Lopez-Gatius, F. and Lopez-Bejar, M., Reproductive performance of dairy cows with ovarian cysts after different GnRH and cloprostenol treatments. Theriogenology, 58: 1337-1348, 2002.

\section{NAGLIS N.}

10. Todoroki, J.,Yamakuchi, H., Mizoshita, K., et al., Restoring ovulation in beef donor cows with ovarian cysts by progesterone-releasing intravaginal silastic devices. Theriogenology, 55: 1919-1932, 2001.

11.Grohn, YT., Erb, H., McCulloch, CE., et al., Epidemiology of reproductive disorders in dairy cattle: associations among host characteristics, disease and production. Prev Vet Med, 8; 25-39, 1990.

12.Uribe, HA., Kennedy, BW., Martin, SW., et al., Genetic parameters for common health disorders of Holstein cows. J Dairy Sci, 78: 421-430, 1995

13. Bartlett, PC., Ngategize, PK., Kaneene, JB., et al., Cystic follicular disease in Michigan Holstein-Friesian cattle: incidence, descriptive epidemiology, and economic impact. Prev Vet Med, 4: 15-33, 1986.

14.Dinsmore, RP., White, ME., Guard, CL., et al., A randomized double blind clinical trial of two GnRH analogs for the treatment of cystic ovaries in dairy cows. Cornell Vet, 77: 235-243, 1987.

15. Yotov, S., Atanasov, A., Bonev, G., Dineva, J., Palova, N., Investigation on some biochemical parameters and effect of hormonal treatment in anoestrous dairy cows with cystic ovarian follicle. Asian Pacific Journal of Reproduction 3: 41-45, 2014.

16. Bartolome, JA., Archbald, LF., Morresey, P., et al. Comparison of synchronization of ovulation and induction of estrus as therapeutic strategies for bovine ovarian cysts in the dairy cow. Theriogenology, 53: 815$825,2000$.

17. Todoroki, J., Noguchi, J., Kikuchi, K., et al., Retrospective analysis of the efficacy of controlled internal drug release in follicular cysts in an embryo donor beef herd. J Reprod Dev, 50: 369-373, 2004. 